\title{
The Effects of Netrin-1 in Patient with Peripheral Neuropathy
}

\author{
Hamid Islampoor ${ }^{*}$ and Roshanmehr Hoshang ${ }^{2}$
}

${ }^{1}$ Department of Biochemistry, School of Medicine, Shiraz University of Medical Sciences, Shiraz, Iran

${ }^{2}$ Department of Biochemistry, School of Medicine, Ahvaz Jundishapur University of Medical Sciences, Ahvaz, Iran

*Corresponding Authors: Hamid Islampoor, Department of Biochemistry, School of Medicine, Shiraz University of Medical Sciences, Shiraz, Iran, E-mail: bidgani777@yahoo.com

Received: 29 January 2018; Accepted: 21 February 2018; Published: 02 March 2018

\begin{abstract}
The Netrin-1 is a molecule of the 63KD-expressible laminin-dependent molecule secreted by neurons in the midline of the ventricular tube of the vertebrate neuronal tube and is involved in the growth and differentiation of the nervous system as well as angiogenesis as an axonal conduction molecule. The topical use of these adhesives over the past three decades has had a significant effect on reducing the volume of bleeding and accelerating tissue repair and reducing the risk of invasive surgeries and their complications, even in the treatment of hemophilia, it is necessary to use blood and coagulation products This product reduces patient complications and costs. These components are harvested from the stored plasma on the day of operation, and after mixing in the operating position, they coagulate after approximately 10 seconds and cause adhesion, prevent bleeding and neural tissue repair.
\end{abstract}

Keywords: Netrin-1; Neural tissue; Peripheral neuropathy

\section{Introduction}

The Netrin- 1 is a molecule of the 63KD-expressible laminin-dependent molecule secreted by neurons in the midline of the ventricular tube of the vertebrate neuronal tube and is involved in the growth and differentiation of the nervous system as well as angiogenesis as an axonal conduction molecule [1]. The neurons of the posterior complex send their axons to special centers in the gray sphincter body. During the development of the fetus, axons develop along the lateral margin of the spinal cord [2]. In the growth of the fetal spinal cord, the niter-1, with its effect on the receptors in neurons axons, directs them to the lateral lateral margin of the spinal cord [3]. 
The Netrin-1 is a member of the family of homologous molecules: Deleted in Colorectal Cancer (DCC) and Uncoordinated-5 homolog (UNC5H) include UNC5H2, UNC5H1, UNC5H3 and UNC5H4. The Netrin-1 and their receptors are expressed in non-neural tissues such as pancreas, lupus and lung glands [4]. Deleted in Colorectal Cancer (DCC) receptors and Uncoordinated-5 homolog (UNC5H), are connected to the Netrin-1 and involved in axonal guidance. They also play a role in regulating the angiogenesis and homeostasis of various tissues. Deleted in Colorectal Cancer (DCC) and Unc-5 homolog receptors in the absence of the Netrin-1, initiate pro-apoptotic signals, thus acting similar to tumor suppressors. Pro-apoptotic signals generated by Deleted in Colorectal Cancer (DCC) receptors and (UNC5H) Unc-5 homolog are protective mechanisms for tumor growth and metastasis [5].

The latter receivers have a dual role in dealing with the Netrin-1, so that by binding the Netrin-1 to their receiver, the signal of cellular survival and proliferation is transmitted, while in the absence of the latter, it induces cell death [6, 7]. The presence of the DCC ligand, the Netrin-1, is necessary to control apoptosis [8, 9]. The pro-apoptotic activity of DCC or UNC5H has no linkage to the ligand, not only in the neuronal cell line used in vitro, but also in most neuronal ex vivo studies $[10,11]$, or in animal models used in vivo, such as Mice, chickens and zebra fish are shown by disabling the Netrin-1, receptors, or both [12-14]. The most commonly used anti- both the DCC and UNC5H2 receptors inhibited the pro-apoptotic effects of these two receptors [15]. Netrin-1 acts as a protector for neurons and inhibits apoptosis in terms of brain damage. These effects are regulated in the nervous system through the interaction of the lowest -1, a glycoprotein secreted, and DCC receptor [16-20].

\section{Material and Methods}

Netrin-1 is a kind of biological product. The topical use of these adhesives over the past three decades has had a significant effect on reducing the volume of bleeding and accelerating tissue repair and reducing the risk of invasive surgeries and their complications, even in the treatment of hemophilia, it is necessary to use blood and coagulation products This product reduces patient complications and treatment costs [21]. The basis of the production of these adhesives is the regeneration of the coagulation process by separating and then mixing the two components of the fibrinogen and active human thrombin plasma [22]. It should be noted that taking fibrin glue from human fibrinogen and bovine thrombin is not recommended because of the complications of cow's thrombin, such as severe allergies, and the stimulation of anti-Factor antibody production and increased risk of other bleeding [23].

Recently, however, netrin-1 and fibrinogen have been prepared without the need for active thrombin [24]. In addition to the two components, the adhesive contains other protein components, including fibronectin and factor 13, which accelerates the tissue repair and the strength of the clot [25]. Sometimes, by adding a condensed platelet to the above compound, you can increase the repair power of these adhesives [26]. In the term, this type of product is called a fibrinous platelet adhesive or a mixture of a platelet gel and a fibrin adhesive [27].

\section{Results}

Netrin-1 and fibrinogen are combined plasma, commercial industrial adhesives after refining hundreds of liters of human plasma [28]. These types of adhesives, despite the high and relatively constant concentrations of fibrinogen and thrombin, are also used Simple and consistency was not favored by developing countries because of high prices and the potential for transmission of infections from aggregate plasma [29]. 
Netrin-1 and fibrinogen can be prepared from a human plasma doner [30]. Autologous adhesives generally do not pose a risk of potentially cumulative commercial adhesives, and are commercially economical for commercial adhesives. In the preparation of these glues, which are also known as blood bank fibrin adhesives, various techniques and special tools and materials are used, some of which, therefore, have the registered name of a business specializing in that method or tool [31].

It should be noted that in the preparation of homologous adhesives, there is no need to perform a plasma phase. Therefore, it is less costly than autologous glue, and secondly, it can be used for a variety of patients and consumers regardless of age, weight, and clinical conditions [32]. Although quarantined plasma is continuously measured, the safest plasma is known, but it still has a risk. There is potential for infection transmission [33].

\section{Discussion}

The use of this type of adhesive in the past 3 to 4 decades, especially in eye surgery, urology, orthopedics, restorative, and dentistry has been welcomed [34]. Even these adhesives can be effective in inherited bleeding disorders [35]. Industrial products from the combined plasma received approval from the FDA in late 1999 and a decade earlier in Europe [36]. However, due to the possibility of transmission of infectious viral infections and perions, as well as high prices, it was not favored in developing countries [37]. Currently, due to the positive and beneficial effects of adhesives fibrin glues in different surgical procedures, autologous preparation of the patient's own plasma The world is welcomed [38].

Netrin-1 and fibrinogen has the following components: 1. A fibrinogenic component with an initial concentration of $20070 \mathrm{mg}$ per $\mathrm{ml}$, a final volume of about $5 \mathrm{ml}$ and a secondary concentration of about $10040 \mathrm{mg} / \mathrm{ml}$. The thrombin component contains a concentration of about 70 to 50 units per milliliter and a volume of about 5 to 7 centimeters. Of course, in some clinical conditions, the third component is a platelet that contains specific growth factors [39]. These components are harvested from the stored plasma on the day of operation, and after mixing in the operating position, they coagulate after approximately 10 seconds and cause adhesion, prevent bleeding and tissue repair [40].

\section{References}

1. Shirasaki R, Mirzayan C, Tessier-Lavigne M, et al. Guidance of circumferentially growing axons by netrindependent and-independent floor plate chemotropism in the vertebrate brain. Neuron 17 (1996): 10791088.

2. Watanabe K, Tamamaki N, Furuta T, et al. Dorsally derived netrin 1 provides an inhibitory cue and elaborates the 'waiting period' for primary sensory axons in the developing spinal cord. Development 133 (2006): 1379-1387.

3. Masuda T, Watanabe K, Sakuma C, et al. Netrin-1 Acts as a Repulsive Guidance Cue for Sensory Axonal Projections toward the Spinal Cord. The Journal of Neuroscience 28 (2008): 10380-10385.

4. Yebra M, Montgomery AM, Diaferia GR, et al. Recognition of the neural chemoattractant Netrin-1 by integrins alpha6beta4 and alpha3beta1 regulates epithelial cell adhesion and migration. Dev Cell 5 (2003): 695-707. 
5. Patrick Mn, Céline G. Netrin-1 and its dependence receptors as original targets for cancer therapy. Current Opinion in Oncology 22 (2010): 46-54.

6. Mehlen P, Rabizadeh S, Snipas SJ,et al. The DCC gene product induces apoptosis by a mechanism requiring receptor proteolysis. Nature 801 (1998): 804-395.

7. Chen YQ, Hsieh JT, Yao F, et al . Induction of apoptosis and G2/M cell cycle arrest by DCC. Oncogene 18 (1999): 2747-2754.

8. Forcet C, Ye X, Granger L,et al. The dependence receptor DCC (Deleted in Colorectal Cancer) defines an alternative mechanism for caspase activation. Proc Natl Acad Sci USA 98 (2001): 3416-3421.

9. Liu J, Yao F, Wu R,et al. Mediation of the DCC apoptotic signal by DIP13 alpha. J Biol Chem 277 (2002): 26281-26285.

10. Furne C, Rama N, Corset V, et al. Netrin-1 is a survival factor during: commissural neuron navigation. Proc Natl Acad Sci USA 105 (2008): 14470-14465.

11. Tang X, Jang SW, Okada M,et al. Netrin-1 mediates neuronal survival through PIKE-L interaction with the dependence receptor UNC5B. Nat Cell Biol 10 (2008): 698-706.

12. Llambi F, Causeret F, Bloch-Gallego E, et al. Netrin-1 acts as a survival factor via its receptors UNC5H and DCC. EMBO J 20 (2001): 2715-2722.

13. Furne C, Rama N, Corset V, et al. Netrin-1 is a survival factor during commissural neuron navigation. Proc Natl Acad Sci USA 105 (2008): 14465-14470.

14. Castets M, Coissieux MM, Delloye-Bourgeois C, et al . Inhibition of endothelial cell. apoptosis by netrin-1 during angiogenesis. Dev Cell 16 (2009): 614-620.

15. Mille F1, Llambi F, Guix C, et al. Interfering with multimerization of netrin-1 receptors triggers tumor cell death. Cell Death Differ 16 (2009): 1344-1351.

16. Wu TW, Li WW, Li H. Netrin-1 attenuates ischemic stroke-induced apoptosis. Meuroscience 156 (2008): 475-482.

17. Fan Y, Shen F, Chen Y, et al. Overexpression of netrin-1 induces neovascularization in the adult mouse brain. J Cereb Blood Flow Metab 28 (2008): 1543-1551.

18. Tang X, Jang SW, Okada M, et al. Netrin-1 mediates neuronal survival through PIKE-L interaction with the dependence receptor UNC5B. Nat Cell Biol 10 (2008): 698-706.

19. Manitt C, Colicos MA, Thompson KM, et al. Widespread expression of netrin-1 by neurons and oligodendrocytes in the adult mammalian spinal cord. J Neurosci 21 (2001): 3911-3922.

20. Low K, Culbertson M, Bradke F, et al. Netrin-1 is a novel myelin-associated inhibitor to axon growth. J Neurosci 28 (2008): 1099-1108.

21. Bergel S. Über Wirkung des Fibrins. Dtsch Med Wochenschr 35 (1909): 663-665.

22. Grey EG. Fibrin as a haemostatic in cerebral surgery. Surg Gynecol Obstet 21 (1915): 452-454.

23. Harvey SC. The use of fibrin paper and forms in surgery. Boston Med Surg J 174 (1916): 658-659.

24. Young JZ, Medawar PB. Fibrin suture of peripheral nerves. Lancet 236 (1940): 126-128.

25. Tarlov IM, Benjamin B. Plasma clot and slk suture of nerves. Surg Gynecol Obstet 76 (1943): $367-374$.

26. Cronkite EP, Lozner EL, Deaver JM. Use of thrombin and fibrinogen in skin grafting. JAMA 124 (1944): 976-978.

27. Matras H. Fibrin seal: the state of the art. J Oral Maxillofac Surg 43 (1985): 605-611. 
28. Sierra DH. Fibrin sealant adhesive systems: a review of their chemistry, material properties and clinical applications. J Biomater Appl 7 (1993): 309-352.

29. Matras H, Dinges HP, Lassmann H, et al. Suture-free interfascicular nerve transplantation in animal experiments. Wien Med Wochenschr 122 (1972): 517-523.

30. Kuderna H, Matras $\mathrm{H}$. The clinical use of the splice of nerve anastamosis in the German reconstruction of more injured peripheral nerves. Wien Klin Wochenschr.

31. Fattahi T, Mohan M, Caldwell GT. Clinical applications of fibrin sealants. J Oral Maxillofac Surg 62 (2004): 218-224.

32. Durham LH, Willatt DJ, Yung MW, et al. A method for preparation of fibrin glue. J Laryngol Otol 101 (1987): 1182-1186.

33. Oz MC, Jeevanandam V, Smith CR, et al. Autologous fibrin glue from intraoperatively collected plateletrich plasma. Ann Thorac Surg 53 (1992): 530-531.

34. Alston SM, Solen KA, Broderick AH, et al. New method to prepare autologous fibrin glue on demand. Transl Res 149 (2007): 187-195.

35. Jackson MR, MacPhee MJ, Drohan WN, et al. Fibrin sealant: current and potential clinical applications. Blood Coagul Fibrinolysis 7 (1996): 737-746.

36. Tredree R, Beierlein W, Debrix I, et al. Evaluating the differences between fibrin sealants: recommendations from an international advisory panel of hospital pharmacists. Eur J Hosp Pharm Sci 12 (2006): 3-9.

37. Kjaergard HK, Trumbull HR. Vivostat system autologous fibrin sealant: preliminary study in elective coronary bypass grafting. Ann Thorac Surg 66 (1998): 482-486.

38. Oswald AM, Joly LM, Gury C, et al. Fatal intraoperative anaphylaxis related to aprotinin after local application of fibrin glue. Anesthesiology 99 (2003): 762-763.

39. Schievink WI, Geoganos SA, Maya MM, et al. Anaphylactic reactions to fibrin sealant injection for spontaneous spinal CSF leaks. Neurology 70 (2008): 885-887.

40. Kon NF, Masumo H, Nakajima S, et al. Anaphylactic reaction to aprotinin following topical use of biological tissue sealant. Masui 43 (1994): 1606-1610 (in Japanese).

Citation: Hamid Islampoor, Roshanmehr Hoshang. The Effects of Netrin-1 in Patient with Peripheral Neuropathy. Archives of Clinical and Medical Case Reports 2 (2018): 40-44.

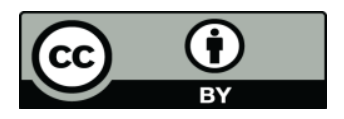

This article is an open access article distributed under the terms and conditions of the

Creative Commons Attribution (CC-BY) license 4.0 